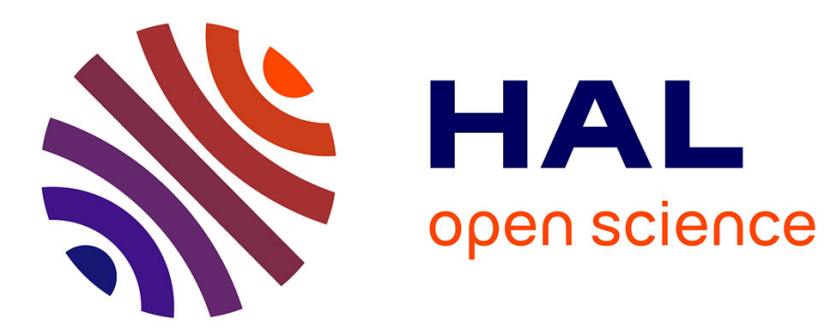

\title{
Progress toward treatments for synaptic defects in autism.
}

Richard Delorme, Elodie Ey, Roberto Toro, Marion Leboyer, Christopher Gillberg, Thomas Bourgeron

\section{To cite this version:}

Richard Delorme, Elodie Ey, Roberto Toro, Marion Leboyer, Christopher Gillberg, et al.. Progress toward treatments for synaptic defects in autism.. Nature Medicine, 2013, 19 (6), pp.685-94. 10.1038/nm.3193 . pasteur-01470299

\section{HAL Id: pasteur-01470299}

https://hal-pasteur.archives-ouvertes.fr/pasteur-01470299

Submitted on 26 Feb 2019

HAL is a multi-disciplinary open access archive for the deposit and dissemination of scientific research documents, whether they are published or not. The documents may come from teaching and research institutions in France or abroad, or from public or private research centers.
L'archive ouverte pluridisciplinaire HAL, est destinée au dépôt et à la diffusion de documents scientifiques de niveau recherche, publiés ou non, émanant des établissements d'enseignement et de recherche français ou étrangers, des laboratoires publics ou privés. 


\title{
Progress toward treatments for synaptic defects in autism
}

\author{
Richard Delorme ${ }^{1-4}$, Elodie Ey ${ }^{1-3}$, Roberto Toro ${ }^{1-3}$, Marion Leboyer ${ }^{5,6}$, Christopher Gillberg $^{7-9}$ \& \\ QIThomas Bourgeron ${ }^{1-3,6^{7}}$
}

Autism spectrum disorder (ASD) encompasses a range of disorders that are characterized by social and communication deficits and repetitive behaviors. For the majority of affected individuals, the cause of ASD remains unknown, but in at least $20 \%$ of the cases, a genetic cause can be identified. There is currently no cure for ASD; however, results from mouse models indicate that some forms of the disorder could be alleviated even at the adult stage. Genes involved in ASD seem to converge on common pathways altering synaptic homeostasis. We propose, given the clinical heterogeneity of ASD, that specific 'synaptic clinical trials' should be designed and launched with the aim of establishing whether phenotype 'reversals' could also occur in humans.

ASD comprises a heterogeneous group of disorders with different etiologies, phenotypic outcomes and ages of onset. In a subset of patients with ASD, mutations of genes related to synaptic function have been identified, suggesting that abnormal neuronal homeostasis is a risk factor for $\mathrm{ASD}^{1,2}$. Studies of the human brain transcriptome have shown that genes associated with synaptic functions may be expressed early during intrauterine development (3-6 months gestational age $)^{3}$. However, the consequences of these alterations in gene expression are only detected as ASD much later, during the first 3 years of life. It is not known whether neuronal circuits expressing these genes can be preserved despite the presence of genetic mutations. An increasing number of studies in mouse models of ASD have shown that certain neuronal defects can be reversed in the mature mouse brain, either by restoring the gene function, decreasing mRNA translation or modulating the balance between excitation and inhibition (Table 1 and Supplementary Table 1). These results challenge the notion that all forms of ASD are irreversible neurodevelopmental disorders ${ }^{4}$. Given the clinical heterogeneity of ASD, we argue that specific synaptic clinical trials should be designed and launched with a view to establishing whether or not similar reversals could also occur in humans.

\footnotetext{
${ }^{1}$ Institut Pasteur, Human Genetics and Cognitive Functjons Unit, Paris, France. ${ }^{2}$ Centre National de la Recherche_Scientifique, URA 2182 'Genes, synapses and cognition', Institut Pasteur, Paris, France. ${ }^{3}$ University Paris Diderot, Sorbonne Paris Cité, Human Genetics and Cognitive Functions, Paris, France. ${ }^{4}$ Assistance Publique-Hôpitaux de Paris, Robert_Debré Hospital, Department of Child and Adolescent Psychiatry, Paris, France. 5 Institut National de la Santé ef de la Recherche Médicale, U955, Psychiatry Genetic Team, Creteil, France.

${ }^{6}$ Fondation FondaMental, France. ${ }^{7}$ Gill berg Neuropsychiatry Centre. Ûniversity of Gothenburg, Göteborg, Sweden. 8Institute of Child Health, University College London, London, UK. 9University of Glasgow, Glasgow, UK. Correspondence should be addressed to T.B. (thomasb@pasteur.fr).
}

Received 3 December 2012; accepted 11 April 2013; published online XX XX 2013; doi:10.1038/nm.3193
The clinical trajectory and heterogeneity of ASD

The very early (premorbid) signs of ASD are still largely unknown, which brings into question whether reversibility is possible and whether there might be a discrete window for reversing the pathological process. Among clinicians, there is agreement that autistic symptoms are relatively stable over time ${ }^{5}$. Nevertheless, over the past decades, several reports have described individuals with autism who were clearly affected in early childhood but emerged as adolescents and adults with relatively ordinary lives and no profound behavioral deficits. In a recent prospective study of 6,975 children with ASD followed from diagnosis through age 14 , six distinct common trajectories of social, communication and repetitive behavior were identified ${ }^{6}$. For example, $21.4 \%$ of the subjects never showed repetitive behaviors, and $8.1 \%$ presented with repetitive behaviors at age 3 but improved as they grew older (Fig. 1). Most of the trajectories remained stable from 4 to 14 years, but with different levels of severity. Interestingly, about one in ten of children with ASD experienced rapid gains in communication and social abilities, moving from severely affected to high functioning ('bloomers').

The core symptoms of ASD are rarely seen in isolation and usually coexist with other psychiatric and medical conditions, including intellectual disability, language disorders, epilepsy, motor control problems, attention-deficit/hyperactivity disorders, tics, anxiety, sleep disorders, gastrointestinal problems and abnormal (too high or too low) response to sensory stimuli. Intensive behavioral interventions have been shown to improve the cognitive and adaptive behaviors of young children with $\mathrm{ASD}^{7}$. However, treatments for ASD need to take into account the extreme degree of etiological and clinical heterogeneity of these conditions and also the possibility that multiple treatments might be needed to target different types of symptoms. The concept of ESSENCE (early symptomatic syndromes eliciting neurodevelopmental clinical examinations) was recently introduced to better take into account the clinical heterogeneity and syndromatic overlap of developmental symptoms that impair children under the age of $3-5$ years $^{8}$.

\section{The relationship between brain development and function}

Neuronal circuits are shaped by genes and the environment throughout life, but there are some critical periods when brain development is particularly sensitive to experience ${ }^{9}$. During early life, these key periods of high brain plasticity involve sensory systems, but also motor functions and cognition ${ }^{10}$. After these 'windows in development', the level of plasticity is reduced ${ }^{9,11}$. This reduced plasticity is linked to the development of myelin or perineuronal networks that drastically curtail neurite outgrowth in the mature brain and also to functional modifications in the excitation-inhibition balance ${ }^{9,11}$. For example, 
PERSPECTIVE

Table 1 Improvement of the phenotypes in mouse models of autism spectrum disorders

\begin{tabular}{|c|c|c|}
\hline Models & & Methods \\
\hline \multirow[t]{2}{*}{$F m r 1^{-/-}$} & Genetic & $\begin{array}{l}\text { Overexpression of } F M R 1 \text { human } \\
\text { gene }^{37 * 38 * 113 *}\end{array}$ \\
\hline & & Reduction of mGluR5 expression $42 *$ \\
\hline
\end{tabular}

Outcomes

Overexpression of $\operatorname{NIgn} 1_{4}^{\mathbb{H}_{1} *}$

Pharmacology MPEP (mGluR5 antagonist) 43,114

Minocycline (matrix metalloproteinase 9 inhibitor) $48 * 49 *$

CTEP (mGluR5 antagonist) 68

Arbaclofen (activation of $\mathrm{GABA}_{\mathrm{B}}$ receptor) 78

Lovastatin (ERK-mediated protein synthesis inhibitor) ${ }^{72}$

Environment Physical enrichment ${ }^{33}$

N/gn3 $3^{-1-} \quad$ Genetic

Reexpression of Nlgn3 in Purkinje cells ${ }^{71 *}$

$\mathrm{NIgn1}^{-/-} \quad \begin{gathered}\text { Pharmacology } \\ \begin{array}{c}\text { D-Cycloserine (NMDAR partial } \\ \text { agonist) }\end{array}\end{gathered}$

Pten $^{-1-} \quad$ Pharmacology Rapamycin (mTOR inhibitor) 64

Shank2-l- Pharmacology D-Cycloserine (NMDAR partial agonist) ${ }^{51}$

CDPPB (mGlur5 positive allosteric modulators $)^{51}$ $\begin{array}{ccc}\text { Cntnap2 }^{-1-} \quad \text { Pharmacology } & \begin{array}{c}\text { Risperidone (dopaminergic D2 } \\ \text { receptor antagonist) }\end{array}{ }^{54}\end{array}$

\begin{tabular}{|c|c|c|}
\hline$c n 1 a^{+1-}$ & Pharmacology & $\begin{array}{l}\text { Clonazepam (positive allosteric } \\
\left.\text { modulator of } \mathrm{GABA}_{A}\right)^{77}\end{array}$ \\
\hline Eif4ebp2-l- & Pharmacology & $\begin{array}{l}\text { 4EGI-1 (selective inhibitor which } \\
\text { prevents elF4E binding to elF4G) }\end{array}$ \\
\hline$T S C 1^{-/-}$ & Pharmacology & Rapamycin (mTOR inhibitor) 61 \\
\hline$T s c 2^{-1-}$ & Pharmacology & Rapamycin (mTOR inhibitor) 61 \\
\hline $\operatorname{ecp} 2 \mathrm{y} /-$ & Genetic & Reactivation of Mecp2 (Cre-lox) ${ }^{4,115}$ \\
\hline
\end{tabular}

Overexpression of BDNF $45 *$

Pharmacology Ampakine CX546 (AMPAR agonist) ${ }^{116}$

Desipramine (norepinephrine reuptake inhibitor) 117,118

Insulin-like growth factor 1 (IGF1R agonist) 34 *

No effect: Motor learning; spatial learning and memory; anxiety; startle response (worse) Improvement: Macroorchidism; activity; social approaches; anxiety toward novel food; PPI

No effect: Macroorchidism

Improvement: Extinction of inhibitory avoidance; plasticity and spine density in visual cortex; basal protein synthesis in hippocampus; audiogenic seizure; body growth

No effect: Spatial learning; interest for novel objects

Partial improvement: Positive puncta for excitatory synapses; number of inhibitory synapses Improvement: Social preference; social contact maintenance; activity; body weight

Partial improvement: Seizure

Improvement: Anxiety in open field; activity; seizure

Improvement: Working memory in Y-maze; anxiety in plus maze; percentage of mushroomshaped spines; dendritic spine length; percentage of short dendritic spines with larger heads; number of USV emitted by a male toward a female

No effect: Motor coordination

Partial improvement: ERK activity; macroorchidism

Improvement: Inhibitory avoidance; startle response to auditory stimuli; activity; spine density in visual cortex; hippocampal LTD (slices)

No effect: Distance in open field; marble burying; motor coordination

Partial improvement: Seizure

Improvement: Basal protein synthesis in hippocampus; AMPA receptor internalization; spine density

Partial improvement: Audiogenic seizures

Improvement: Excessive protein synthesis, epileptiform activity in hippocampus (in vitro), hyperexcitability in visual cortex (in vitro)

Improvement: Anxiety in open field; habituation to novel objects; basal dendritic branching; basal dendritic length; spine density; spine maturation; GluR1 levels in visual cortex

Partial improvement: Motor coordination

Improvement: mGluR $1 \alpha$ protein level; mGluR $1 \alpha$ synaptic abundance; DHPG-induced phospho-GluA2 signals; ectopic synapse formation

Improvement: Self-grooming

No effect: Cell polarity

Partial improvement: Macrocephaly

Improvement: Social interactions; anxiety; soma hypertrophy

No effect: Social recognition

Partial improvement: Preference for social interactions Improvement: NDMA/AMPA ratio

No effect: Social recognition; pup retrieval; repeated jumping; anxiety in plus maze; activity Partial improvement: Preference for social interactions

Improvement: NMDA/AMPA ratio; LTP and LTD at hippocampal Schaffer-collateral-

CA1-pyramidal synapses; NMDAR signaling in whole brain and synaptosomes

No effect: Sensory hypersensitivity; preference for social interactions

Partial improvement: Spontaneous alternations

Improvement: Nesting behavior; self-grooming; hyperactivity

Improvement: Social interest; free social interactions; fear conditioning; inhibitory transmission

Improvement: Social preference; NIgn protein amounts; excitation-inhibition balance

Partial improvement: Survival; macrocephaly; hindlimb clasping

Improvement: Spatial learning; context discrimination; L-LTP

Partial improyement: Activity; gait; hindlimb clasping; tremor; respiratory function; (body weight)

Improvement: LTP; activity; body weight; brain weight; neuronal size

Partial improvement: Brain size

Improvement: Activity

Partial improvement: BDNF levels

Improvement: Respiratory function

No effect: Activity; body weight; head size

Partial improvement: Respiratory function; lifespan

Improvement: Tyrosine hydrolase expression in brainstem

Partial improvement: Lifespan; activity; respiratory function; heart rate; brain weight;

PSD-95 concentration in motor cortex; spine density on motor cortex neurons; excitatory synaptic transmission in sensory motor cortex neurons; plasticity in cortical circuits 
PER SPECTIVE

Table 1 Continued

\begin{tabular}{|c|c|c|c|}
\hline \multicolumn{2}{|l|}{ Models } & \multirow{2}{*}{$\begin{array}{l}\text { Methods } \\
\text { Insulin87 }\end{array}$} & \multirow{2}{*}{$\begin{array}{l}\text { Outcomes } \\
\text { No effect: baseline breathing; breathing response to hypoxia } \\
\text { Worsening: weight gain; heart rate decline; blood glucose; breathing response to hypoxia; } \\
\text { lifespan }\end{array}$} \\
\hline & & & \\
\hline & & $\begin{array}{l}\text { Fingolimod (sphingosine-1 } \\
\text { phosphatase receptor modulator) } 53\end{array}$ & $\begin{array}{l}\text { No effect: BDNF levels in cerebellum } \\
\text { Partial improvement: Lifespan; hindlimb clasping; BDNF levels in cortex, hippocampus, } \\
\text { striatum; wet weight of striatum } \\
\text { Improvement: Locomotor activity; motor coordination }\end{array}$ \\
\hline & Environment & Physical enrichment ${ }^{81}$ & No effect: Motor coordination; BDNF levels in cerebellum \\
\hline Del15q11-13 & Genetic & $\begin{array}{l}\text { Reduction of CaMKII inhibitory } \\
\text { phosphorylation } 117 *\end{array}$ & $\begin{array}{l}\text { Improvement: Motor coordination; spatial learning and memory; contextual fear } \\
\text { conditioning; kinase activity; body weight; audiogenic seizure; LTP }\end{array}$ \\
\hline Ube3am-/p+ & Pharmacology & $\begin{array}{l}\text { PD } 158780 \text { and PD168393 (ERBBB } \\
\text { inhibitor) } 118\end{array}$ & Improvement: LTP, long-term memory in fear conditioning \\
\hline Dup17q11.2 & Environment & Physical and social enrichment 83 & $\begin{array}{l}\text { No effect: Social dominance; olfactory habituation/dishabituation; stereotypes } \\
\text { Partial improvement: Social recognition; fear conditioning; anxiety } \\
\text { Improvement: Motor coordination }\end{array}$ \\
\hline
\end{tabular}

*Treatment administered during development. PPI, prepulse inhibition; LTD, Iong-term depression; LTP, Iong-term potentiation; PAG, periaqueducal gray; USV, ultrasonic vocalizations; DHPG, dihydroxyphenylglycine.

local GABAergic circuits modulate visual cortical plasticity in early postnatal life ${ }^{9}$, and similar fine-tuning of excitation and inhibition is also crucial for correct auditory cortical development ${ }^{12}$. Autism was proposed as a critical-period disorder ${ }^{13}$ after it was shown that mutations in several genes associated with ASD may affect the early inhibition-excitation balance, thus shifting the timing of critical periods or even completely obliterating such periods of high neuronal plasticity. Dysfunction in auditory, visual and somatosensory information processing might even be the primary factor driving aberrant development of socialization and communication skills in $\mathrm{ASD}^{13}$. Thus, if a gene is required at a specific developmental stage, its reactivation at a later stage outside the critical period might be insufficient to reverse the consequence of its early loss.

Genetic studies have identified hundreds of genes associated with $\mathrm{ASD}^{2,14,15}$. These genes have roles in various physiological processes, such as chromatin remodeling, metabolism, translation and synaptogenesis. It is speculated,

Figure 1 Time course of gene expression in the human brain and clinical features observed in patients with ASD. (a) Early signs of ASD are detected in the first 2 years of life. (b-d) Trajectories of 6,975 children with ASD, followed from diagnosis through to the age of 14 years. Six distinct common trajectories were defined for each core symptom of ASD (social interaction, communication and restrictive pattern of interests). The $y$ axis represents the level of functioning (from 0: low functioning to 100: high functioning). The percentages in parentheses indicate the proportion of subjects that exhibited the corresponding trajectory. Data are taken from ref. 6. (e,f) Developmental trajectories of genes associated with cell proliferation, doublecortin-immunopositive cells (DCX), dendrites, synapses and myelinitaion in the cerebellar cortex and the neocortex of the human brain. The time course of gene mRNA expression is summarized by the first principal component (PC1) of the indicated set of genes (expressed as the percentage of the maximum) across age. Data are taken from ref. 3 . however, that these genes may converge into pathways affecting distinct neuronal functions ${ }^{2}$. Neuronal and/or synaptic homeostasis could be one of these functions, which would help explain why opposite morphological or functional defects in ASD sometimes lead to similar clinical outcomes ${ }^{16,17}$. For example, a reduction in the number of dendrites was observed in Rett and tuberous sclerosis syndromes, whereas a high density of dendrites was reported in fragile $\mathrm{X}$ syndrome ${ }^{16}$. These three genetic syndromes have a very high rate of associated ASD symptoms (up to $60 \%$ of affected individuals for fragile X and Rett syndromes, and up to $50 \%$ of individuals with tuberous sclerosis syndrome). Similarly, some mutations increase or reduce excitatory currents, whereas some increase or decrease inhibitory currents. For example, Shank3 (encoding SH3 and multiple

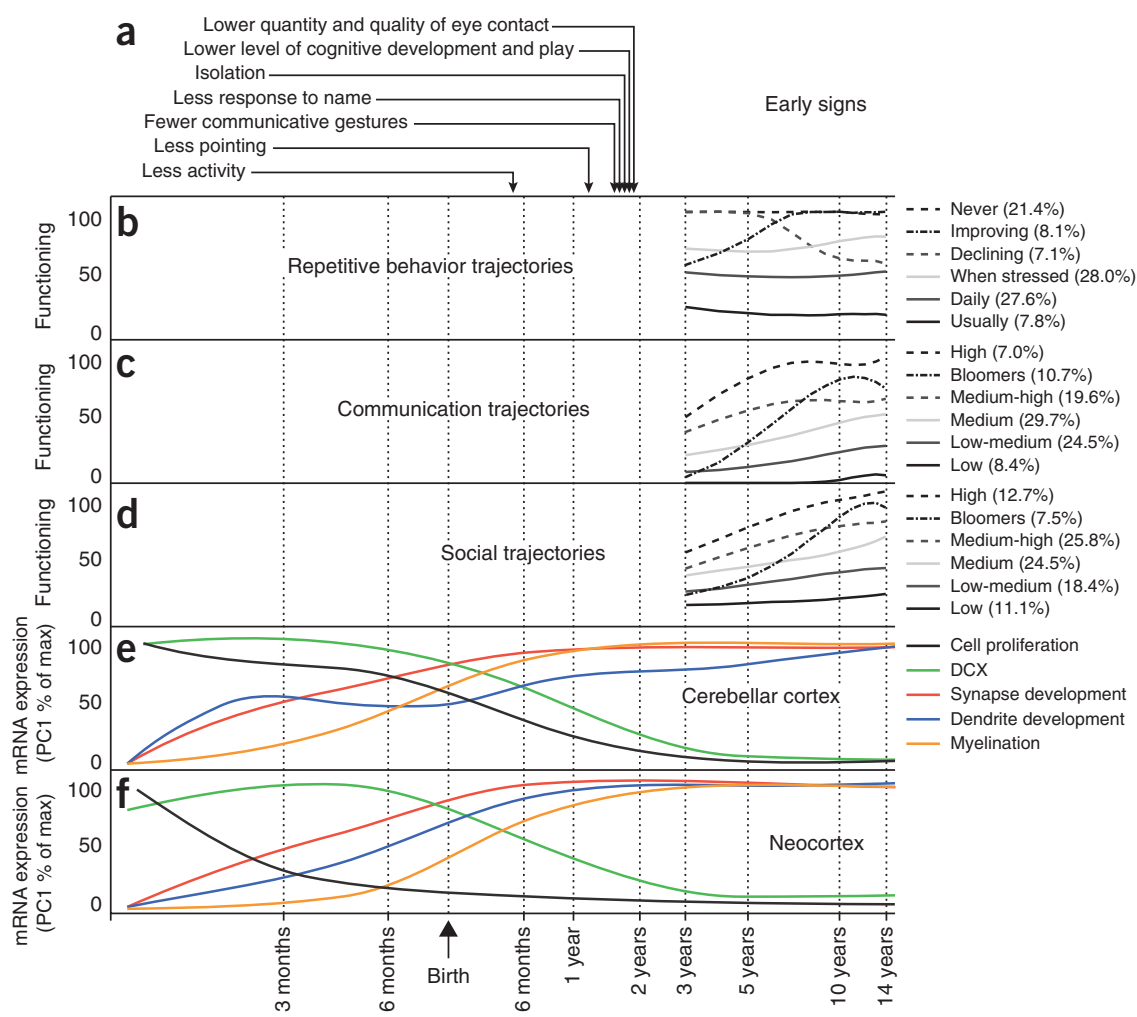




\section{PERSPECTIVE}

ankyrin-repeat domains 3) homozygous-knockout mice show a reduction in the frequency and amplitude of their excitatory postsynaptic currents ${ }^{18}$, whereas Nlgn3 (encoding neuroligin 3) knock-in R451C mice show an increase in the frequency of their inhibitory post-synaptic currents ${ }^{19}$.

Interestingly, several genes associated with ASD are modulated by neuronal activity ${ }^{20}$, suggesting that they may mediate experiencedependent circuit modifications ${ }^{2}$. For example, a subset of genes associated with ASD (such as NLGN3, NRXN1 (encoding neurexin 1), SHANK3, PTEN (encoding phosphatase and tensin homolog), TSC2 (encoding tuberous sclerosis 2) and NF1 (encoding neurofibromin 1)) are targets of the fragile $\mathrm{X}$ mental retardation protein (FMRP, encoded by FMR1) responsible for fragile $\mathrm{X}$ syndrome and regulation of neuronal translation ${ }^{21}$.

It remains largely unknown in which phases of development mutations found in ASD produce a detectable phenotype. In rodents, most genes involved in synaptogenesis are strongly expressed after birth and reach a plateau in adulthood ${ }^{22-24}$. In contrast, in humans, the genes involved in dendrite and synapse formation are switched on very early in utero, and the amounts of transcripts reach a plateau at 6-9 months of fetal life ${ }^{3}$. This may also be the case for most ASD susceptibility genes. But, even if these genes are expressed at a very early stage of brain development, the impact of their mutation on brain function seems to be delayed and only observable at a later stage (Fig. 1). This delay between the initial expression of the gene and the functional impact of the mutation might have several different causes.

First, genetic redundancy might occur at early stages of development. Mutations usually affect a single allele of a gene, and the mutated gene may belong to a family of genes (for example, the SHANK family). Thus, the second allele, or other members of the same gene family (for example, SHANK1, SHANK2 and SHANK3) might preserve the gene's functions early on, but its late functions cannot be compensated. In such a case, the basic wiring of the brain might not be affected. Such compensation and functional redundancy of synaptic proteins during development has been observed, for example, in Dlg1 (also known as SAP97) knockout mice ${ }^{25}$.

Second, the functional consequences of the mutations may only be detectable when the networks are fully mature (that is, in postnatal life, at an early stage of development). In this case, defects in cellular differentiation, cellular migration or long-distance axon guidance might be detected only when a specific ability, such as spoken language, develops. Among the proteins associated with ASD that could affect neuronal connectivity are the contactins, the semaphorins and the SHANK proteins. Contactins and semaphorins are directly involved in neuritogenesis and axon guidance, but they are also found at the synapse. SHANK3 is important for dendrite formation but is also abundant in the growth cone of axons during migration, suggesting that it may also be necessary for long-distance connectivity ${ }^{26}$. In this case, the mutations might affect the hard wiring of neuronal networks, and recovery from an ASD after the brain has fully matured might be more difficult to achieve. This was recently shown for a mouse model lacking SYNGAP1, a synaptic protein crucial for dendritic spine development. Inducing SYNGAP1 mutations after the critical period of spine development had a minimal impact on spines, and repairing the defect in mouse adulthood did not improve behavioral phenotypes ${ }^{27}$.

Third, the apparent delay between gene expression and phenotypic outcome might also be a result of the challenge of detecting early phenotypic features, for example, during pregnancy. After birth, most children with ASD experience a decline in the acquisition of developmental milestones from 6 to 36 months ${ }^{28}$, with less pointing by 12 months, fewer communicative gestures and responses to name by 18 months and less eye contact by 24 months (Fig. 1). Differences in patterns of head growth ${ }^{29}$ and aberrant white matter organization ${ }^{30}$ have been occurred in some cases during the first year of life, and differences in event-related potential to face processing ${ }^{31}$ and in electroencephalographic activity ${ }^{32}$ have been detected at as early as 6-10 months of age. These features are not specific to ASD but might be early signs of abnormal synaptic homeostasis and of a variety of neurodevelopmental dysfunctions.

To obtain the proof of principle for reversion of a specific neuronal defect, mouse models carrying similar mutations to those identified in individuals with ASD have been generated that allow the mutated genes to be conditionally reactivated in the mature brain. Such mice can be used to test the potential for reversibility, but species-specific differences might limit direct predictions in humans, and thus results from clinical trials are required to provide reliable information about the possibility of alleviating the disorder.

\section{From mice to humans: developing treatments for ASD}

Numerous studies have investigated the possibility of treating the phenotype in mouse models of fragile X syndrome and Rett syndrome as well in mice containing mutations of synaptic proteins associated with ASD (Table 1 and Supplementary Table 1). Strategies to alleviate the abnormal phenotype include genetic manipulation and cellular therapy, pharmacological intervention and environmental stimulation. Most studies have first focused on the comorbidities observed in mouse models of ASD, such as presence of seizures, abnormal locomotor activity and anxiety ${ }^{4,33,34}$. Recent studies have undertaken a more comprehensive behavioral characterization of the core symptoms of ASD by exploring, for example, social interactions or ultrasonic vocalizations as a possible paradigm for speech deficiency ${ }^{35,36}$.

Genetic and cellular therapeutic strategies. Experiments using genetic interactions (crossing mouse strains that carry mutations in different genes) have been used to modulate the expression of the genes and pathways of interest in ASD. In the fragile X model lacking the Fmr1 gene, expression of a functional human FMR1 gene restored social behavior and sensory gating ${ }^{37-39}$. Interestingly, overexpression of neuroligin 1, a synaptic cell adhesion molecule mutated in some cases of $\mathrm{ASD}^{40}$, can also improve social behavior in fragile $\mathrm{X}$ model mice but has no positive effect on learning or memory ${ }^{41}$. Similar experiments have been performed to compensate for the downstream effects of mutations: excessive mRNA translation following mGluR5 signaling, overexpression of amyloid- $\beta$ protein or overexpression of the striatal-enriched protein tyrosine phosphatase in the fragile $\mathrm{X}$ mouse model ${ }^{42-44}$ and reduced expression of brain-derived neurotrophic factor (BDNF) in the Rett syndrome mouse model ${ }^{45}$. These studies have achieved partial improvements: reduction in the number of seizures, reduction of body weight, decreased gait abnormalities, improved locomotor activity and reduced social and nonsocial anxiety (Table 1). Crossing mouse lines, however, provides no information on the reversibility of the phenotype in adult mice, as the compensation occurs from an early stage of development.

Genetic manipulation and cellular therapy strategies have also been used to reverse neuroanatomical and behavioral abnormalities in mice modeling ASD. In a pioneering experiment, the group of Adrian Bird created a mouse model of Rett syndrome in which the endogenous Mecp2 gene (encoding methyl CpG-binding protein 2) was silenced but could be conditionally activated ${ }^{4}$. They showed that 


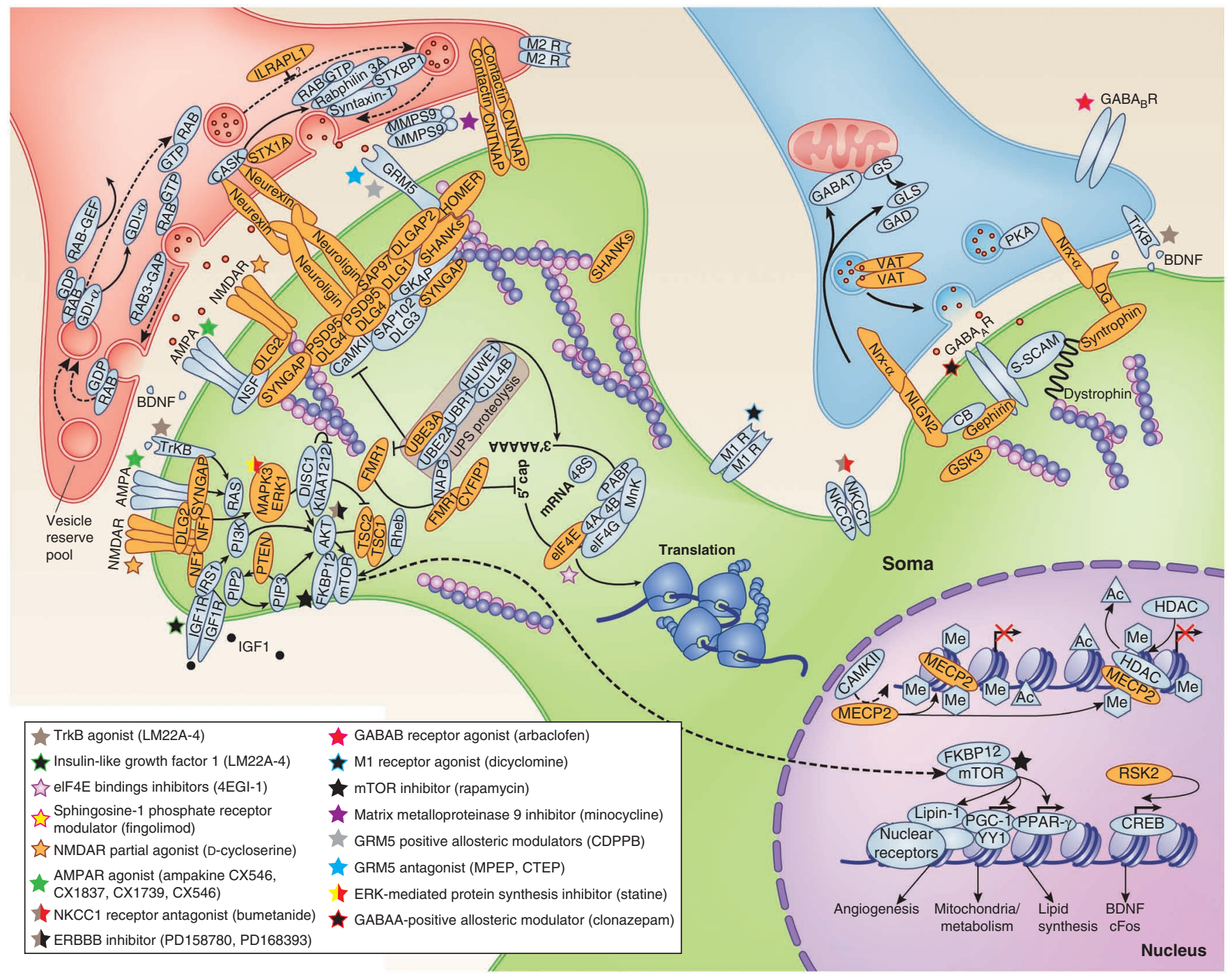

Figure 2 The synaptic proteins involved in ASD and the drugs that have been tested in mouse models of ASD or in clinical trials. Schematic representation of pre- and post-synaptic proteins located at glutamatergic and GABAergic synapses. Proteins reported to be associated with ASD are in orange. Factors involved in the pathways that the ASD-associated proteins participate in are shown in blue. Pharmacological compounds used to reverse core symptoms of autism in mouse models and patients are tagged with a star. The functional link between these proteins were shown experimentally (for example: FMRP targets distinct mRNA sequence elements to regulate expression of several proteins associated with ASD 109 and elF4E overexpression leads to increased translation of neuroligins ${ }^{110}$, which are postsynaptic proteins that are causally linked to ASDs ${ }^{111}$ ). The pathways associated with ASD are reviewed in refs. 2,56,112.

activation of $M e c p 2$ in $70 \%$ of neurons in both immature and mature adult mice reversed many morphological defects in the motor cortex, including neuronal size and dendritic complexity. This led to a marked improvement in respiratory and sensorimotor functions, including breathing pattern, grip strength and balance-beam and rotarod performance ${ }^{4}$. In a follow-up study, reexpression of Mecp2 only in catecholaminergic cells was sufficient to improve survival, general activity, motor coordination and seizure-like cortical activity in $M e c p 2^{+/-}$mice ${ }^{46}$. Recently, Derecki et al. ${ }^{47}$ used transplantation of wild-type bone marrow to introduce microglial cells into the Mecp2 knockout mouse model of Rett syndrome. This resulted in increased lifespan, normalization of breathing patterns, reduction of apnea, normalization of body weight and improved locomotor activity in these mice ${ }^{47}$. Taken together, these findings support the view that MECP2 does not necessarily play a pivotal part in brain development but may instead be required to maintain full neurological function once development has occurred ${ }^{4}$.

Pharmacological therapeutic strategies. Pharmacological interventions for ASD have been facilitated by the fact that most of the molecules tested in mice have already been used in humans for other purposes (for example, ampakine (CX546), dicyclomine, minocycline, desipramine, D-cycloserine, fingolimod). Lifespan, seizure, learning, memory and anxiety have been shown to be robustly ameliorated by pharmacological treatments ${ }^{48-53}$. In a recent study on BTBR $\mathrm{T}+\mathrm{tf} / \mathrm{J}$ mice, a partial improvement of social interest was even possible with ampakine treatment ${ }^{36}$. However, treatment of ASD core symptomsdecreased social interaction and increased stereotypy-may be more challenging. For example, in Cntnap2 knockout mice, risperidone can alleviate increased repetitive behavior, but not social 


\section{PERSPECTIVE}

deficits $^{54}$, a dissociation similar to what is seen in humans treated with the same drug 55 .

Empirical treatments that target two pathways in ASD (mRNA translation and excitation-inhibition balance) are now emerging and have shown some promise (Fig. 2). The possibility that targeting mRNA translation in ASD might be therapeutically beneficial was suggested by reports of aberrant mRNA translation of synaptic proteins in people with $\mathrm{ASD}^{56}$. The evidence supporting this theory includes the identification of mutations affecting several proteins (NF1, TSC1, TSC2 and PTEN) that normally inhibit mRNA translation through the phosphoinositide 3-kinase-mammalian target of rapamycin (PI3K-mTOR) signaling pathway or in proteins directly involved in the inhibition of mRNA translation at the synapse (FMR1, CYFIP1 and ELF4E) in patients with $\mathrm{ASD}^{57-60}$. In addition, an excess of mRNA translation (20\%) was observed in the Fmrl knockout mouse model of fragile $\mathrm{X}$ syndrome. On the basis of these findings, two main strategies have been used to inhibit translation in mouse models of ASD.

The first strategy is repression of the PI3K-mTOR signaling pathway using molecules such as rapamycin. Rapamycin successfully reduced cognitive impairment and social behavior deficit in mouse models of tuberous sclerosis ${ }^{61-63}$ and improved behavior in adult mice with a deletion of PTEN ${ }^{64}$. Unexpectedly, even gross anatomical abnormalities such as neuronal hypertrophy were reversed at the adult stage ${ }^{64}$. In patients with tuberous sclerosis, rapamycin led to a marked reduction in the volume of astrocytomas and in seizure frequency, suggesting that this might be an alternative therapy to neurosurgical resection that could increase the quality of life for patients ${ }^{65}$. However, the efficacy of rapamycin in ameliorating behavioral abnormalities, including those that are regarded as ASD core symptoms, remains to be further investigated, and the possibility of adverse events occurring in patients receiving such treatments also remains to be determined ${ }^{66}$.

The second strategy is repression of mRNA translation by inhibiting the action of the group 1 metabotropic glutamate receptors mGluR1 and mGluR5. A 50\% reduction in mGluR5 expression decreased excess translation and improved behavior in the fragile $\mathrm{X}$ mouse model $^{42}$. The mGluR5 antagonist MPEP (2-methyl-6-(phenylethynyl)pyridine) can rescue altered dendritic spine morphology as well as behavioral and cognitive deficits in different models of fragile X syndrome (reviewed in ref. 67). Chronic treatments with CTEP, a high affinity, longacting and orally bioavailable mGluR inhibitor, restored cognitive functions, ameliorated auditory hypersensitivity, aberrant dendritic spine density and overactive extracellular signal-regulated kinase (ERK) and mTOR signaling, and partially corrected the macroorchidism observed in male mouse models of fragile $\mathrm{X}$ syndrome ${ }^{68}$.

In humans, a recent randomized, double-blind, crossover study of 30 males with fragile $\mathrm{X}$ syndrome-all of them with severe autistic symptoms-was performed to evaluate the effects of the mGluR5 antagonist AFQ056 (ref. 69). Despite a lack of improvement of the group of patients $(n=30)$ as a whole, secondary analysis revealed that a subset of patients with a fully methylated FMR1 gene $(n=7)$ showed a benefit as measured with the aberrant behavior checklist (mean decrease -27.8 in patients with full methylation versus +3.2 in patients with partial methylation), highlighting the importance of identifying relevant biomarkers to assess therapeutic benefits. Three different mGluR5 antagonists, AFQ056 (Novartis), RO4917523 (HoffmannLa Roche) and STX107 (Seaside Therapeutics) are currently being investigated in advanced clinical trials (phases 2-3) or will start to be investigated shortly. Studies in mice suggest that mGluR antagonists could also be efficacious for treating other synaptic defects. MPEP can reduce self-grooming behavior in BTBR mice, an inbred genetic mouse model of $\mathrm{ASD}^{70}$. Nlgn 3 knockout mice show ectopic synapse formation and perturbed mGluR-dependent synaptic plasticity, a hallmark of fragile X syndrome. These phenotypes could be rescued by reexpression of Nlgn 3 in juvenile mice, again highlighting the possibility of reverting neuronal circuit alterations in autism after the completion of development ${ }^{71}$. Lovastatin, an inhibitor of ERK-mediated protein synthesis currently used in treatment of hypercholesterolemia, has recently been shown to reduce audiogenic seizures in a mouse model of fragile $X^{72}$. Finally, minocycline, a broad-spectrum tetracycline antibiotic, also represses mRNA translation ${ }^{48}$. In fragile X mice, treatment with minocycline for 1 month after birth normalized the dendritic spine defects and improved behavior and cognition. In addition, the number of ultrasonic vocalizations of males in the presence of estrus females was restored to that of wild-type mice ${ }^{73}$. Two open trials of minocycline in patients with fragile $\mathrm{X}$ syndrome demonstrated significant improvements, advocating for placebo-controlled trials of this $\mathrm{drug}^{74,75}$.

A second pathway in ASD that could be modulated by drugs concerns the synaptic excitation-inhibition balance. Several gene associated with ASD seem to be involved in the formation of excitatory and inhibitory synapses, such as those encoding neuroligins and neurexins. In addition, mutations in genes associated with epilepsy, such as $S C N 1 A$, which encodes a voltage-gated sodium channel, have been found in patients with $\mathrm{ASD}^{76}$. In mice haploinsufficient for $S c n 1 a$, treatment with low-dose clonazepam, a positive allosteric modulator of $\mathrm{GABA}_{\mathrm{A}}$ receptors, completely reversed the abnormal social behaviors and deficits in fear memory ${ }^{77}$. Activation of the $\mathrm{GABA}_{\mathrm{B}}$ receptor by arbaclofen decreased mRNA translation in the cortex of fragile $\mathrm{X}$ mice and corrected the increased spine density ${ }^{78}$. In humans, a recent randomized, double-blind, placebo-controlled crossover study using arbaclofen in 63 subjects with a full mutation in the FMR1 gene showed a slight improvement of social abilities measured by the aberrant behavior checklist social avoidance subscale but no significant benefit in the primary outcome measures quantified by the aberrant behavior checklist irritability subscale ${ }^{79}$. Another example is provided by the Nlgn1 knockout mouse, which shows a reduced NMDA/AMPA ratio at corticostriatal synapses ${ }^{52}$. In these mice, administration of the NMDA receptor (NMDAR) partial co-agonist D-cycloserine rescued the repetitive grooming phenotype. In Shank 2 knockout mice, direct stimulation of NMDARs with D-cycloserine normalized NMDAR function and improved social interaction ${ }^{51}$. Recently, an alternative and interesting new strategy to modulate the excitation-inhibition balance emerged that used the diuretic chloride-transporter antagonist bumetanide, which reduces intracellular chloride concentration, reinforcing GABAergic inhibition. A recent clinical trial in patients with ASD showed improvements calling for larger-scale randomized trials to test this drug ${ }^{80}$.

Environmental and social enrichment strategies. Finally, environmental enrichment has been used to reverse abnormal phenotypes in mouse models of ASD. Changing objects and adding a running wheel in the cage decreased anxiety and restored dendritic length and branching, spine density and maturation in a mouse model of fragile $\mathrm{X}^{33}$. The same strategy has been extensively used in mouse models of Rett syndrome and has restored locomotor activity, improved learning deficits and anxiety and increased BDNF expres$\operatorname{sion}^{81}$. Another strategy that might hold promise is social enrichment. Housing BTBR mice with highly social C57BL/6 mice has been reported to enhance the social interactions in the BTBR strain ${ }^{82}$. A combination of both social and physical enrichment rescued motor 
Figure 3 Strategies for synaptic clinical trials in ASD. (a) To reduce genetic and clinical heterogeneity, individuals with ASD should be placed into groups on the basis of their affected genes and pathways by using whole-genome sequencing. In parallel, deep phenotyping of these subgroups of patients should be used to identify intermediate phenotypes and biomarkers more closely related to the synaptic defects. (b) Animal models and iPSCs can be used to better characterize the synaptic defects present in patients. They are likely to be powerful tools for identification of robust assays that can provide the readout necessary for standardized highthroughput drug screening (safety and efficacy). (c) Patients with similar synaptic defects should be enrolled in pharmacological trials to test the efficacy and the safety of compounds selected previously (in $\mathbf{b}$ ). The categories of synaptic defects are taken from the results obtained in the current mouse models of ASD (increased synaptic density in the fragile $\mathrm{X}$ mouse model, decreased synaptic density in Rett syndrome, decreased excitatory çurrent in the Shank1 and Shank3ß knockout mouse). The outcome of such trials will be based on clinical instruments measuring the improvements in quality of life and core symptoms of autism, but also on biomarkers identified previously in this group of patients (in a).

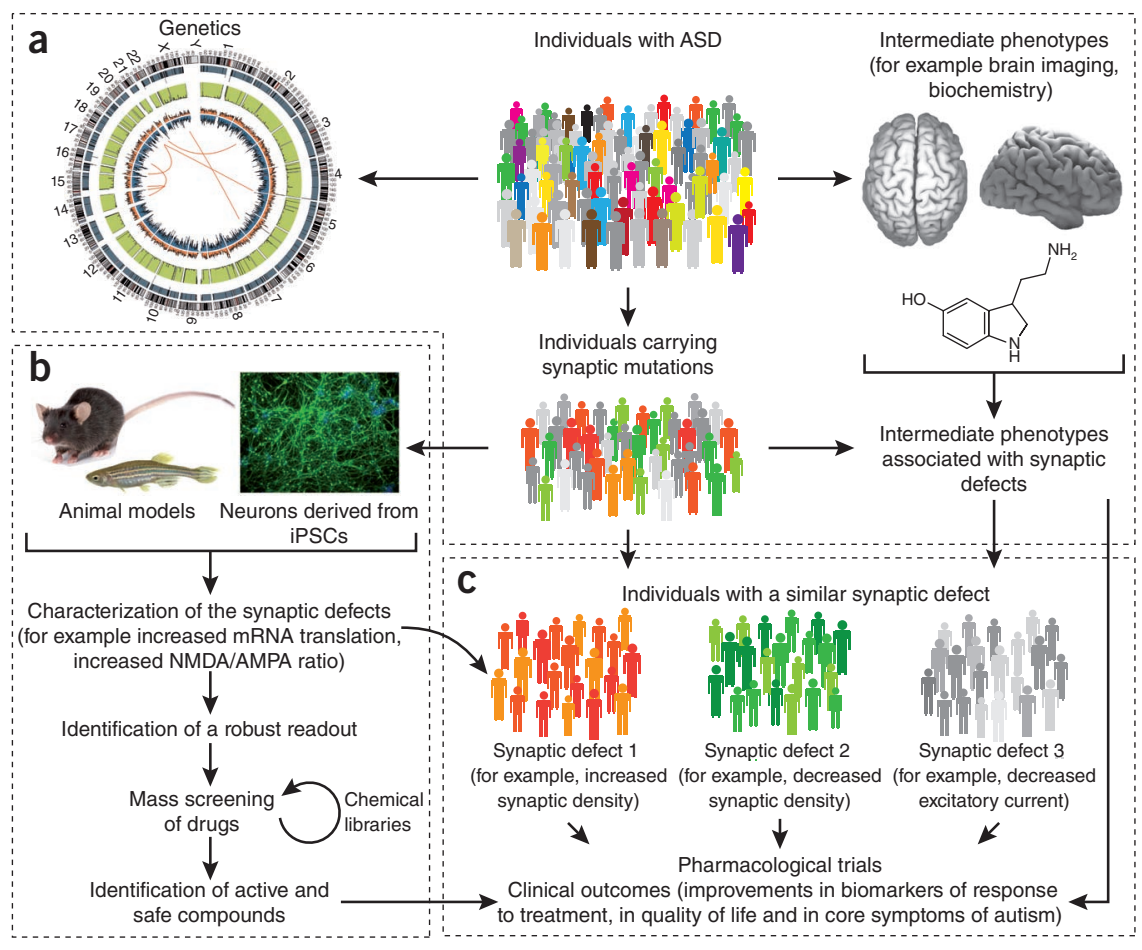

defects, improved learning and memory, reduced aggressive behavior and relieved anxiety in a mouse model of Potocki-Lupski syndrome. This clinical syndrome is caused by a 3.7-Mb duplication in chromosome $17 \mathrm{p} 11.2$ and is characterized by neurobehavioral abnormalities, intellectual disability and ASD in $70-90 \%$ of affected individuals ${ }^{83}$. Interestingly, in the mouse model study, social enrichment increased stereotypic repetitive behavior in both mutant and wild-type mice, suggesting that this phenotype is sensitive to overstimulation. To our knowledge, no studies have tested 'behavioral strategies', that is task repetition and regular training through repeated exposure with highly social strains as demonstrators or initiators, to improve the behavior of mutant mice in social interaction tasks. It would be interesting to test whether such behavioral interventions, which have demonstrated their efficacy in patients with $\mathrm{ASD}^{84}$, could positively affect the behavior of mouse models of ASD.

Taken together, these results indicate that some synaptic and behavioral defects can be restored in adult mice even after the end of the critical periods of development. Nevertheless, some points remain to be further investigated. Many of these studies were performed on one genetic background, with small groups of mice per treatment, in some cases only in males (details in Supplementary Table 1). The stability of the improvement and the side effects of the treatments were not always documented. It was also shown that the behavioral consequence of a mutation might also be different across generations ${ }^{85}$ or on different backgrounds ${ }^{86}$. The investigation and publication of possible worsening of phenotypes in mouse models should also be encouraged to complement knowledge about treatments and dose effects ${ }^{87}$. Finally, none of these studies investigated a combination of pharmacological intervention and a modified (enriched) environment to test for potential optimization of treatment. The key questions now are whether the positive results obtained in rodents can be translated to humans and how best to design trials to test therapeutic modalities that have shown promise in animal models of ASD.
Future directions for clinical trials

Only two drugs, risperidone and aripiprazole, have been approved by the US Food and Drug Administration for the treatment of ASD. Although these drugs serve to manage challenging and repetitive behaviors, they have little effect on the social communication deficit observed in $\mathrm{ASD}^{88}$. Developing knowledge-based treatments for ASD will have to take into account the high genetic and clinical heterogeneity of these conditions ${ }^{89}$. To date, the most frequently mutated genes affect less than $0.1-1 \%$ of the affected subjects, that is, approximately $8,000-80,000$ individuals in all G8 countries. Standard randomized placebo-controlled clinical trials in hundreds of patients will therefore be difficult to achieve for ASD, and specific clinical trials designed for rare diseases need to be devised ${ }^{90}$.

One of the main challenges for clinical trials in ASD is the considerable degree of heterogeneity, which could mask the effects of the tested treatment. Furthermore, the clinical scores most frequently used to measure treatment efficacy in clinical trials might be too focused on the core ASD symptoms and do not necessarily reflect improvements in quality of life ${ }^{91}$. For example, most of the pharmacological trials for ASD in ClinicalTrials.gov $(n=153)$ are using the clinical global instrument (33\%), which measures clinical improvement, and the aberrant behavior checklist (31\%), which measures the comorbid problem behaviors associated with ASD. Both instruments do not take into account the quality of life of patients, and an improvement measured by these instruments does not always correlate with better functioning in everyday life ${ }^{92}$. Therefore, one possibility would be to have quality-of-life scales as the primary outcome scales and autism checklists as the secondary ones. Or, when designing new studies, researchers could flag from the beginning that both types of scales should be preset as the (combined) primary outcome variable.

We propose that three major steps are needed to improve the efficacy of clinical trials for patients with ASD and synaptic defects (Fig. 3): (i) obtain more homogenous subgroups of individuals with ASD, as determined on the basis of the affected genes or pathways 
rather than on the clinical phenotype; (ii) identify relevant clinical outcomes and biomarkers related to these subgroups (for example, neuronal, biochemical and brain imaging markers); and (iii) increase knowledge of the natural history of this subgroup of patients to identify, for example, periods of symptoms worsening.

The benefit of a clinical trial strategy focused on patients selected for their synaptic defects is to reduce the genetic, but also the phenotypic, heterogeneity. The strategy of selecting patients on the basis of the affected genes or pathways is currently used for 'syndromic' forms of ASD, such as tuberous sclerosis and fragile X syndrome. Using the same strategy, specific synaptic clinical trials should now be launched for ASD. As a first step, patients enrolled in these synaptic clinical trials should be selected using whole-genome sequencing to identify the causative or contributory synaptic mutations as well as putative modifier genes. In many cases, patients with inherited deletions of $16 \mathrm{p}$ or de novo SHANK2 mutations, for example, carry additional mutations, and the presence of multiple hits might be indeed the rule rather than the exception in $\mathrm{ASD}^{93,94}$. A better knowledge of these modifier genes will inform clinicians and researchers on responses to treatment. For example, the identification of multiple genetic hits in a patient might explain why he or she will not fully respond to the treatment whereas other patients without these additional genetic mutations will.

Animal models and patient-specific induced pluripotent stem cells (iPSCs) should be used to inform researchers on the synaptic defects present in each patient and thereby enable them to enroll patients with different causative mutations but with apparently similar synaptic defects (for example, decreased or increased synaptic density, excitation-inhibition imbalance) in the clinical trials. Specific neural cell subtypes differentiated from patient-specific iPSCs are likely to be a powerful tool for evaluating the hierarchy of cellular vulnerability in these diseases and the potential efficacy of therapies being tested. As an example, a specific assay for dysfunction of synaptic proteins, such as SHANK, remains to be determined. Cellular models expressing deleterious SHANK3 mutations suggest that modifications of dendritic spine morphology via an actin-dependent mechanism are part of the mutant phenotype ${ }^{26}$. Similarly, SHANK3 mutant mice show a hypertrophy of medium spiny neurons with an increase in the complexity of dendritic arbors and total dendritic length ${ }^{17,18}$. An in-depth characterization of the synaptic defect associated with each type of genetic mutation is crucial for two main reasons: first, the identification of a robust readout is necessary for drug screening; second, patients with mutations in similar genes might actually show the opposite synaptic defects, as observed in Shank2 (increased NMDA) and Shank3 (decreased NMDA) knockout mice ${ }^{17,18,51}$. If these results are confirmed in iPSCs from patients with these mutations, then patients with SHANK2 and SHANK3 mutations should be enrolled in two different synaptic clinical trials to test potential disease-modifying therapies.

Finally, a better knowledge on the natural history of each subgroup of patients is crucial for designing a synaptic clinical trial. For example, most patients with de novo or truncating mutations in SHANK3 show an early regression before 36 months and a worsening during adolescence, which correlates with a frequent emergence of epilepsy ${ }^{95}$. SHANK3 mutations have also been identified in individuals developing adult-onset SHANK3 related-disorders, such as schizophrenia and bipolar disorders ${ }^{96,97}$. To better understand this variability in clinical outcome and trajectories of the patients, large-scale initiatives are currently ongoing. The Simons Variation in Individuals Project (Simons VIP) aims to identify and study a large number of individuals with a deletion or duplication of chromosome 16p11.2 that increases the risk of developing neurodevelopmental disorders ${ }^{98}$. The Rett Rare
Disease Clinical Research Center natural history study has enrolled more than 800 patients and led to a redefinition of the critical periods of deterioration of patients and the emergence of ritualized and stereotypic behaviors $^{99}$. These careful analyses of genetically defined ASD subtypes should allow detailed phenotypic comparisons within and among these groups to clarify genotype-phenotype correlations.

\section{Recruiting the functional allele: a possible ASD therapy?} The proposed strategy of synaptic clinical trials for ASD should lead to personalized treatments by taking into account the genetic synaptic defect present in the patient. In this line, the observation that abnormal gene dosage (deletion or duplication) seems to play a key part in ASD could be an advantage for finding new treatments ${ }^{2}$. In contrast to X-linked or autosomal recessive traits, for which the gene product is often absent, in most patients with ASD for which a genetic cause is known, only one allele is affected by copy number variations or two alleles carry weak mutations but are still functional ${ }^{100}$. Given these observations, one promising route for treatment is to activate the expression of the remaining functional allele (in the case of a deletion) or to slightly repress the expression of the gene (in the case of a duplication). This strategy was recently used for Angelman's syndrome, a disorder affecting an imprinted genomic region on chromosome $15 \mathrm{q} 11-\mathrm{q} 13$ that is caused by deletion or mutation of the maternal allele of $U B E 3 A$. Using an unbiased screen in primary cortical neurons from mice, Huang et al. ${ }^{101}$ identified several topoisomerase inhibitors that unsilence the paternal allele of UBE3A. Such molecules could therefore reactivate the functional, but dormant, allele of $U B E 3 A$ in patients with Angelman's syndrome. More generally, the amount of synaptic proteins is regulated by transcription ${ }^{102}$, splicing ${ }^{103}$, mRNA transport $^{104}$, translation ${ }^{105}$ and degradation ${ }^{106}$. A better knowledge of the factors that regulate each of these regulatory steps might help to identify new targets for restoring the amount of specific synaptic proteins in patients. In addition, given that several genes associated with ASD are regulated by neuronal activity ${ }^{20}$, it is most likely that a combination of pharmacological treatments (that restore the amount of synaptic proteins) and behavioral treatments (that stimulate specific neuronal circuits) might show the most benefit for patients.

\section{Conclusions}

There is increasing support for the notion that customized treatments could lead to recovery in some patients with ASD, which may spur revision of views on the stability of ASD phenotypes. In addition, further in-depth molecular pathophysiological characterization of ASDs that are not directly linked to synaptic dysfunction (for example defects in chromatin remodeling ${ }^{107}$ or metabolism ${ }^{108}$ ) should be carried out to investigate the possibility of reversing phenotypes. An integrated approach, which brings together cellular and animal models and knowledge-based clinical trials, will be key to furthering understanding of which affected genes and pathways in ASD can be efficiently recovered and will also provide a basis for developing new therapies.

Note: Supplementary information is available in the online version of the paper.

\section{ACKNNOWLEDGMENTS}

We thank D. DiGregorio and I. Cloez-Tayarini for critical reading of the manuscript and G. Huguet for the illustrations. This work was funded by the Institut Pasteur, the Bettencourt-Schueller foundation, Centre National de la Recherche Scientifique, University Paris Diderot, ANR (ANR-08-MNPS-037-01SynGen), Neuron-ERANET (EUHF-AUTISM), the Fondation de France, the Conny-Maeva Charitable Foundation, the Cognacq Jay Foundation, the Orange Foundation, the Fondamental Foundation and the Innovative Medicines Initiative Joint Undertaking under grant agreement no. 115300, the resources of which 
are composed of financial contribution from the European Union's Seventh

Q25 Framework Programme (FP7/2007 - 2013) and EFPIA companies in kind contribution.

\section{COMPETING FINANCIAL INTERESTS}

The authors declare no competing financial interests.

Reprints and permissions information is available online at http://www.nature.com/ reprints/index.html.

1. Ramocki, M.B. \& Zoghbi, H.Y. Failure of neuronal homeostasis results in common neuropsychiatric phenotypes. Nature 455, 912-918 (2008).

2. Toro, R. et al. Key role for gene dosage and synaptic homeostasis in autism spectrum disorders. Trends Genet. 26, 363-372 (2010).

3. Kang, H.J. et al. Spatio-temporal transcriptome of the human brain. Nature $\mathbf{4 7 8}$, 483-489 (2011).

4. Guy, J., Gan, J., Selfridge, J., Cobb, S. \& Bird, A. Reversal of neurological defects in a mouse model of Rett syndrome. Science 315, 1143-1147 (2007).

5. Constantino, J.N. et al. Developmental course of autistic social impairment in males. Dev. Psychopathol. 21, 127-138 (2009).

6. Fountain, C., Winter, A.S. \& Bearman, P.S. Six developmental trajectories characterize children with autism. Pediatrics 129, e1112-e1120 (2012).

7. Dawson, G. et al. Randomized, controlled trial of an intervention for toddlers with autism: the Early Start Denver Model. Pediatrics 125, e17-e23 (2010).

8. Gillberg, C. The ESSENCE in child psychiatry: Early Symptomatic Syndromes Eliciting Neurodevelopmental Clinical Examinations. Res. Dev. Disabil. 31, 1543-1551 (2010).

9. Hensch, T.K. Critical period plasticity in local cortical circuits. Nat. Rev. Neurosci. 6, 877-888 (2005).

10. Kuhl, P.K. Brain mechanisms in early language acquisition. Neuron $67,713-727$ (2010).

11. Hensch, T.K. Critical period regulation. Annu. Rev. Neurosci. 27, 549-579 (2004)

12. Sun, Y.J. et al. Fine-tuning of pre-balanced excitation and inhibition during auditory cortical development. Nature 465, 927-931 (2010)

13. LeBlanc, J.J. \& Fagiolini, M. Autism: a "critical period" disorder? Neural Plast. 2011, 921680 (2011).

14. Abrahams, B.S. \& Geschwind, D.H. Advances in autism genetics: on the threshold of a new neurobiology. Nat. Rev. Genet. 9, 341-355 (2008).

15. Devlin, B. \& Scherer, S.W. Genetic architecture in autism spectrum disorder. Curr. Opin. Genet. Dev. 22, 229-237 (2012).

16. Auerbach, B.D., Osterweil, E.K. \& Bear, M.F. Mutations causing syndromic autism define an axis of synaptic pathophysiology. Nature 480, 63-68 (2011).

17. Schmeisser, M.J. et al. Autistic-like behaviours and hyperactivity in mice lacking ProSAP1/Shank2. Nature 486, 256-260 (2012).

18. Peça, J. et al. Shank3 mutant mice display autistic-like behaviours and striatal dysfunction. Nature 472, 437-442 (2011).

19. Tabuchi, K. et al. A neuroligin-3 mutation implicated in autism increases inhibitory synaptic transmission in mice. Science 318, 71-76 (2007).

20. Ebert, D.H. \& Greenberg, M.E. Activity-dependent neuronal signalling and autism spectrum disorder. Nature 493, 327-337 (2013).

21. Darnell, J.C. et al. FMRP stalls ribosomal translocation on mRNAs linked to synaptic function and autism. Cell 146, 247-261 (2011).

22. Sunkin, S.M. et al. Allen Brain Atlas: an integrated spatio-temporal portal for exploring the central nervous system. Nucleic Acids Res. 41, D996-D1008 (2012)

23. Boeckers, T.M. et al. Proline-rich synapse-associated protein-1/cortactin binding protein 1 (ProSAP1/CortBP1) is a PDZ-domain protein highly enriched in the postsynaptic density. J. Neurosci. 19, 6506-6518 (1999).

24. Song, J.Y., Ichtchenko, K., Sudhof, T.C. \& Brose, N. Neuroligin 1 is a postsynaptic cell-adhesion molecule of excitatory synapses. Proc. Natl. Acad. Sci. USA 96, 1100-1105 (1999).

25. Howard, M.A., Elias, G.M., Elias, L.A., Swat, W. \& Nicoll, R.A. The role of SAP97 in synaptic glutamate receptor dynamics. Proc. Natl. Acad. Sci. USA 107, 3805-3810 (2010).

26. Durand, C.M. et al. SHANK3 mutations identified in autism lead to modification of dendritic spine morphology via an actin-dependent mechanism. Mol. Psychiatry 17, 71-84 (2012)

27. Clement, J.P. et al. Pathogenic SYNGAP1 mutations impair cognitive development by disrupting maturation of dendritic spine synapses. Cell 151, 709-723 (2012).

28. Landa, R.J., Gross, A.L., Stuart, E.A. \& Faherty, A. Developmental trajectories in children with and without autism spectrum disorders: the first 3 years. Child Dev. 84, 429-442 (2013).

29. Redcay, E. \& Courchesne, E. When is the brain enlarged in autism? A metaanalysis of all brain size reports. Biol. Psychiatry 58, 1-9 (2005)

30. Wolff, J.J. et al. Differences in white matter fiber tract development present from 6 to 24 months in infants with autism. Am. J. Psychiatry 169, 589-600 (2012).

31. Tierney, A.L., Gabard-Durnam, L., Vogel-Farley, V., Tager-Flusberg, H. \& Nelson, C.A. Developmental trajectories of resting EEG power: an endophenotype of autism spectrum disorder. PLOS ONE 7, e39127 (2012).
32. McCleery, J.P., Akshoomoff, N., Dobkins, K.R. \& Carver, L.J. Atypical face versus object processing and hemispheric asymmetries in 10-month-old infants at risk for autism. Biol. Psychiatry 66, 950-957 (2009).

33. Restivo, L. et al. Enriched environment promotes behavioral and morphological recovery in a mouse model for the fragile X syndrome. Proc. Natl. Acad. Sci. USA 102, 11557-11562 (2005).

34. Tropea, D. et al. Partial reversal of Rett Syndrome-like symptoms in MeCP2 mutant mice. Proc. Natl. Acad. Sci. USA 106, 2029-2034 (2009).

35. Ey, E., Leblond, C.S. \& Bourgeron, T. Behavioral profiles of mouse models for autism spectrum disorders. Autism Res. 4, 5-16 (2011).

36. Silverman, J.L., Oliver, C.F., Karras, M.N., Gastrell, P.T. \& Crawley, J.N. AMPAKINE enhancement of social interaction in the BTBR mouse model of autism. Neuropharmacology 64, 268-282 (2013)

37. Peier, A.M. et al. (Over)correction of FMR1 deficiency with YAC transgenics: behavioral and physical features. Hum. Mol. Genet. 9, 1145-1159 (2000).

38. Paylor, R., Yuva-Paylor, L.A., Nelson, D.L. \& Spencer, C.M. Reversal of sensorimotor gating abnormalities in Fmr1 knockout mice carrying a human FMR1 transgene. Behav. Neurosci. 122, 1371-1377 (2008).

39. Spencer, C.M., Graham, D.F., Yuva-Paylor, L.A., Nelson, D.L. \& Paylor, R. Social behavior in Fmr1 knockout mice carrying a human FMR1 transgene. Behav. Neurosci. 122, 710-715 (2008).

40. Glessner, J.T. et al. Autism genome-wide copy number variation reveals ubiquitin and neuronal genes. Nature 459, 569-573 (2009).

41. Dahlhaus, R. \& El-Husseini, A. Altered Neuroligin expression is involved in social deficits in a mouse model of the fragile X syndrome. Behav. Brain Res. 208 , 96-105 (2010).

42. Dölen, G. et al. Correction of fragile $X$ syndrome in mice. Neuron 56, 955-962 (2007).

43. Westmark, C.J. et al. Reversal of fragile $X$ phenotypes by manipulation of AßPP/ A levels in Fmr1KO mice. PLOS ONE 6, e26549 (2011).

44. Goebel-Goody, S.M. et al. Genetic manipulation of STEP reverses behavioral abnormalities in a fragile X syndrome mouse model. Genes Brain Behav. 11, 586-600 (2012).

45. Chang, Q., Khare, G., Dani, V., Nelson, S. \& Jaenisch, R. The disease progression of Mecp2 mutant mice is affected by the level of BDNF expression. Neuron 49 , 341-348 (2006).

46. Lang, M. et al. Selective preservation of MeCP2 in catecholaminergic cells is sufficient to improve the behavioral phenotype of male and female Mecp2deficient mice. Hum. Mol. Genet. 22, 358-371 (2013).

47. Derecki, N.C. et al. Wild-type microglia arrest pathology in a mouse model of Rett syndrome. Nature 484, 105-109 (2012).

48. Bilousova, T.V. et al. Minocycline promotes dendritic spine maturation and improves behavioural performance in the fragile $\mathrm{X}$ mouse model. J. Med. Genet. 46, 94-102 (2009).

49. Rotschafer, S.E., Trujillo, M.S., Dansie, L.E., Ethell, I.M. \& Razak, K.A. Minocycline treatment reverses ultrasonic vocalization production deficit in a mouse model of fragile X syndrome. Brain Res. 1439, 7-14 (2012).

50. Veeraragavan, S. et al. Genetic reduction of muscarinic M-4 receptor modulates analgesic response and acoustic startle response in a mouse model of fragile $X$ syndrome (FXS). Behav. Brain Res. 228, 1-8 (2012).

51. Won, $\mathrm{H}$. et al. Autistic-like social behaviour in Shank2-mutant mice improved by restoring NMDA receptor function. Nature 486, 261-265 (2012).

52. Blundell, J. et al. Neuroligin-1 deletion results in impaired spatial memory and increased repetitive behavior. J. Neurosci. 30, 2115-2129 (2010).

53. Deogracias, R. et al. Fingolimod, a sphingosine-1 phosphate receptor modulator, increases BDNF levels and improves symptoms of a mouse model of Rett syndrome. Proc. Natl. Acad. Sci. USA 109, 14230-14235 (2012).

54. Peñagarikano, O. et al. Absence of CNTNAP2 leads to epilepsy, neuronal migration abnormalities, and core autism-related deficits. Cell 147, 235-246 (2011).

55. McCracken, J.T. et al. Risperidone in children with autism and serious behavioral problems. N. Engl. J. Med. 347, 314-321 (2002).

56. Kelleher, R.J. III \& Bear, M.F. The autistic neuron: troubled translation? Cell 135, 401-406 (2008).

57. Ehninger, D. \& Silva, A.J. Rapamycin for treating tuberous sclerosis and autism spectrum disorders. Trends Mol. Med. 17, 78-87 (2011).

58. Butler, M.G. et al. Subset of individuals with autism spectrum disorders and extreme macrocephaly associated with germline PTEN tumour suppressor gene mutations. J. Med. Genet. 42, 318-321 (2005).

59. Neves-Pereira, M. et al. Deregulation of EIF4E: a novel mechanism for autism. J. Med. Genet. 46, 759-765 (2009).

60. Conti, S. et al. Phosphatase and tensin homolog (PTEN) gene mutations and autism: literature review and a case report of a patient with Cowden syndrome, autistic disorder, and epilepsy. J. Child Neurol. 27, 392-397 (2012).

61. Ehninger, D. et al. Reversal of learning deficits in a $\mathrm{TsC2}^{+/-}$mouse model of tuberous sclerosis. Nat. Med. 14, 843-848 (2008).

62. Tsai, P.T. et al. Autistic-like behaviour and cerebellar dysfunction in Purkinje cell Tsc1 mutant mice. Nature 488, 647-651 (2012).

63. Carson, R.P., Van Nielen, D.L., Winzenburger, P.A. \& Ess, K.C. Neuronal and glia abnormalities in Tsc1-deficient forebrain and partial rescue by rapamycin. Neurobiol. Dis. 45, 369-380 (2012).

64. Zhou, J. et al. Pharmacological inhibition of mTORC1 suppresses anatomical, cellular, and behavioral abnormalities in neural-specific Pten knock-out mice. J. Neurosci. 29, 1773-1783 (2009). 
65. Franz, D.N. et al. Efficacy and safety of everolimus for subependymal giant cell astrocytomas associated with tuberous sclerosis complex (EXIST-1): a multicentre, randomised, placebo-controlled phase 3 trial. Lancet 381, 125-132 (2013).

66. Bissler, J.J. et al. Sirolimus for angiomyolipoma in tuberous sclerosis complex or lymphangioleiomyomatosis. N. Engl. J. Med. 358, 140-151 (2008).

67. Castrén, E., Elgersma, Y., Maffei, L. \& Hagerman, R. Treatment of neurodevelopmental disorders in adulthood. J. Neurosci. 32, 14074-14079 (2012).

68. Michalon, $A$. et al. Chronic pharmacological mGlu5 inhibition corrects fragile $X$ in adult mice. Neuron 74, 49-56 (2012).

69. Jacquemont, $S$. et al. Epigenetic modification of the FMR1 gene in fragile $X$ syndrome is associated with differential response to the mGluR5 antagonist AFQ056. Sci. Transl. Med. 3, 64ra1 (2011).

70. Silverman, J.L., Tolu, S.S., Barkan, C.L. \& Crawley, J.N. Repetitive self-grooming behavior in the BTBR mouse model of autism is blocked by the mGluR5 antagonist MPEP. Neuropsychopharmacology 35, 976-989 (2010).

71. Baudouin, S.J. et al. Shared synaptic pathophysiology in syndromic and nonsyndromic rodent models of autism. Science 338, 128-132 (2012).

72. Osterweil, E.K. et al. Lovastatin corrects excess protein synthesis and prevents epileptogenesis in a mouse model of fragile X syndrome. Neuron 77, 243-250 (2013).

73. Rotschafer, S.E., Trujillo, M.S., Dansie, L.E., Ethell, I.M. \& Razak, K.A. Minocycline treatment reverses ultrasonic vocalization production deficit in a mouse model of fragile X syndrome. Brain Res. 1439, 7-14 (2012).

74. Paribello, C. et al. Open-label add-on treatment trial of minocycline in fragile $X$ syndrome. BMC Neurol. 10, 91 (2010).

75. Utari, A. et al. Side effects of minocycline treatment in patients with fragile $X$ syndrome and exploration of outcome measures. Am. J. Intellect. Dev. Disabil. 115, 433-443 (2010).

76. O'Roak, B.J. et al. Exome sequencing in sporadic autism spectrum disorders identifies severe de novo mutations. Nat. Genet. 43, 585-589 (2011).

77. Han, S. et al. Autistic-like behaviour in $\mathrm{Scnla} \mathrm{a}^{+-}$mice and rescue by enhanced GABA-mediated neurotransmission. Nature 489, 385-390 (2012).

78. Henderson, $C$. et al. Reversal of disease-related pathologies in the fragile $X$ mouse model by selective activation of $\mathrm{GABA}_{\mathrm{B}}$ receptors with arbaclofen. Sci. Transl. Med. 4, 152ra128 (2012).

79. Berry-Kravis, E.M. et al. Effects of STX209 (arbaclofen) on neurobehavioral function in children and adults with fragile $X$ syndrome: a randomized, controlled, phase 2 trial. Sci. Transl. Med. 4, 152 ra127 (2012).

80. Lemonnier, E. et al. A randomised controlled trial of bumetanide in the treatment of autism in children. Transl. Psychiatry 2, e202 (2012).

81. Kondo, M. et al. Environmental enrichment ameliorates a motor coordination deficit in a mouse model of Rett syndrome-Mecp2 gene dosage effects and BDNF expression. Eur. J. Neurosci. 27, 3342-3350 (2008).

82. Yang, M., Perry, K., Weber, M.D., Katz, A.M. \& Crawley, J.N. Social peers rescue autismrelevant sociability deficits in adolescent mice. Autism Res. 4, 17-27 (2011)

83. Lacaria, M., Spencer, C., Gu, W., Paylor, R. \& Lupski, J.R. Enriched rearing improves behavioral responses of an animal model for CNV-based autistic-like traits. Hum. Mol. Genet. 21, 3083-3096 (2012).

84. Dawson, G. et al. Early behavioral intervention is associated with normalized brain activity in young children with autism. J. Am. Acad. Child Adolesc. Psychiatry 51, 1150-1159 (2012).

85. Ey, E. et al. Absence of deficits in social behaviors and ultrasonic vocalizations in later generations of mice lacking neuroligin4. Genes Brain Behav. 11, 928-941 (2012).

86. Bernardet, M. \& Crusio, W.E. Fmr1 KO mice as a possible model of autistic features. Scientific World Journal 6, 1164-1176 (2006).

87. Pitcher, M.R. et al. Insulinotropic treatments exacerbate metabolic syndrome in mice lacking MeCP2 function. Hum. Mol. Genet. published online, http://dx.doi. org/10.1093/hmg/ddt111 (2013).

88. McPheeters, M.L. et al. A systematic review of medical treatments for children with autism spectrum disorders. Pediatrics 127, e1312-e1321 (2011).

89. Spooren, W., Lindemann, L., Ghosh, A. \& Santarelli, L. Synapse dysfunction in autism: a molecular medicine approach to drug discovery in neurodevelopmental disorders. Trends Pharmacol. Sci. 33, 669-684 (2012).

90. Tambuyzer, E. Rare diseases, orphan drugs and their regulation: questions and misconceptions. Nat. Rev. Drug Discov. 9, 921-929 (2010).

91. King, B.H. et al. Lack of efficacy of citalopram in children with autism spectrum disorders and high levels of repetitive behavior: citalopram ineffective in children with autism. Arch. Gen. Psychiatry 66, 583-590 (2009).
92. Kamio, Y., Inada, N. \& Koyama, T. A nationwide survey on quality of life and associated factors of adults with high-functioning autism spectrum disorders. Autism 17, 15-26 (2013).

93. Girirajan, S. et al. Phenotypic heterogeneity of genomic disorders and rare copynumber variants. N. Engl. J. Med. 367, 1321-1331 (2012).

94. Leblond, C.S. et al. Genetic and functional analyses of SHANK2 mutations suggest a multiple hit model of autism spectrum disorders. PLoS Genet. 8, e1002521 (2012).

95. Phelan, K. \& McDermid, H.E. The 22q13.3 deletion syndrome (Phelan-McDermid syndrome). Mol. Syndromol. 2, 186-201 (2012).

96. Verhoeven, W.M., Egger, J.I., Willemsen, M.H., de Leijer, G.J. \& Kleefstra, T. Phelan-McDermid syndrome in two adult brothers: atypical bipolar disorder as its psychopathological phenotype? Neuropsychiatr. Dis. Treat. 8, 175-179 (2012).

97. Gauthier, J. et al. De novo mutations in the gene encoding the synaptic scaffolding protein SHANK3 in patients ascertained for schizophrenia. Proc. Natl. Acad. Sci. USA 107, 7863-7868 (2010).

98. Simons Vip Consortium. Simons Variation in Individuals Project (Simons VIP): a genetics-first approach to studying autism spectrum and related neurodevelopmental disorders. Neuron 73, 1063-1067 (2012).

99. Percy, A.K. et al. Rett syndrome diagnostic criteria: lessons from the Natural History Study. Ann. Neurol. 68, 951-955 (2010).

100. Yu, T.W. et al. Using whole-exome sequencing to identify inherited causes of autism. Neuron 77, 259-273 (2013).

101. Huang, H.S. et al. Topoisomerase inhibitors unsilence the dormant allele of Ube3a in neurons. Nature 481, 185-189 (2012).

102. Sando, R. III et al. HDAC4 governs a transcriptional program essential for synaptic plasticity and memory. Cell 151, 821-834 (2012).

103. Li, Q., Lee, J.A. \& Black, D.L. Neuronal regulation of alternative pre-mRNA splicing. Nat. Rev. Neurosci. 8, 819-831 (2007).

104. Doyle, M. \& Kiebler, M.A. Mechanisms of dendritic mRNA transport and its role in synaptic tagging. EMBO J. 30, 3540-3552 (2011).

105. Swanger, S.A. \& Bassell, G.J. Dendritic protein synthesis in the normal and diseased brain. Neuroscience 232C, 106-127 (2012).

106. Waites, C.L. et al. Bassoon and Piccolo maintain synapse integrity by regulating protein ubiquitination and degradation. EMBO J. 32, 954-969 (2013).

107. O'Roak, B.J. et al. Multiplex targeted sequencing identifies recurrently mutated genes in autism spectrum disorders. Science 338, 1619-1622 (2012).

108. Novarino, G. et al. Mutations in BCKD-kinase lead to a potentially treatable form of autism with epilepsy. Science 338, 394-397 (2012).

109. Ascano, M. Jr. et al. FMRP targets distinct mRNA sequence elements to regulate protein expression. Nature 492, 382-386 (2012).

110. Gkogkas, C.G. et al. Autism-related deficits via dysregulated elF4E-dependent translational control. Nature 493, 371-377 (2013).

111. Jamain, S. et al. Mutations of the $\mathrm{X}$-linked genes encoding neuroligins NLGN3 and NLGN4 are associated with autism. Nat. Genet. 34, 27-29 (2003).

112. Bill, B.R. \& Geschwind, D.H. Genetic advances in autism: heterogeneity and convergence on shared pathways. Curr. Opin. Genet. Dev. 19, 271-278 (2009).

113. Spencer, C.M., Graham, D.F., Yuva-Paylor, L.A., Nelson, D.L. \& Paylor, R. Social behavior in Fmr1 knockout mice carrying a human FMR1 transgene. Behav. Neurosci. 122, 710-715 (2008).

114. Yan, Q.J., Rammal, M., Tranfaglia, M. \& Bauchwitz, R.P. Suppression of two major fragile $X$ syndrome mouse model phenotypes by the mGluR5 antagonist MPEP. Neuropharmacology 49, 1053-1066 (2005).

115. Giacometti, E., Luikenhuis, S., Beard, C. \& Jaenisch, R. Partial rescue of MeCP2 deficiency by postnatal activation of MeCP2. Proc. Natl. Acad. Sci. USA 104, 1931-1936 (2007).

116. Ogier, M. et al. Brain-derived neurotrophic factor expression and respiratory function improve after ampakine treatment in a mouse model of Rett syndrome. J. Neurosci. 27, 10912-10917 (2007).

117. Roux, J.C. \& Villard, L. Pharmacological treatment of Rett syndrome improve breathing and survival in a mouse model. M S-. Med. Sci. (Paris) 23, 805-807 (2007).

118. Zanella, S. et al. Oral treatment with desipramine improves breathing and life span in Rett syndrome mouse model. Respir. Physiol. Neurobiol. 160, 116-121 (2008). 